\title{
Um Estudo de Caso sobre a Educação Infantil, Pobreza e Desigualdade Social no Município de Afrânio- PE
}

\author{
Ricardo de Araujo Rodrigues ${ }^{1}$, Aítla Lidiane Hermógenes de Souza Jatobá
}

\begin{abstract}
Resumo: A Educação Infantil é a primeira etapa da Educação Básica tendo como propósito o desenvolvimento integral da criança de zero a cinco anos de idade. Neste contexto, o presente trabalho consiste num estudo de caso, realizado através de uma pesquisa qualitativa por meio da análise do Plano Municipal de Educação - PME 20152025, dados do Sistema Integrado de Monitoramento Execução e Controle/ Plano de Ações Articuladas - SIMECPAR Instituto Brasileiro de Geografia e Estatística- IBGE. O estudo desses documentos oportunizou uma reflexão acerca das politicas educacionais no âmbito da educação infantil, pobreza e desigualdade social no município de Afrânio- PE, convidando o leitor a refletir também sobre o que interfere nas políticas educacionais de fortalecimento da Educação Infantil, a situação do programa Proinfância, apontando propostas para sanar a falta de creches, o aumento de atendimento de crianças nesta modalidade de ensino. Nesta perspectiva, é imprescindível também, admitir que a existência persistente dos pobres nas escolas traz análises fundamentais para as práticas educacionais, sendo que os indivíduos pobres são notados por grande parte da sociedade, ligados à violência e a crimes e que não são dotados de valores, cabendo um ensino que combate a imagem pejorativa do pobre, rompendo com um currículo moralista, fortalecendo valores de justiça e cidadania, garantindo uma educação inclusiva.
\end{abstract}

Palavras-chave: Educação Infantil. Pobreza. Desigualdade Social.

\section{A Case Study on Children Education, Poverty and Social Inequality in Afrânio - PE}

\begin{abstract}
The Early Childhood Education is the first stage of Basic Education with the purpose of the integral development of children from zero to five years of age. In this context, the present work consists of a case study, carried out through a qualitative research through the analysis of the Municipal Education Plan - PME 2015-2025, data of the Integrated System of Monitoring Execution and Control / Plan of Articulated Actions - SIMEC- PAR Brazilian Institute of Geography and Statistics - IBGE. The study of these documents provided a reflection on educational policies in the area of early childhood education, poverty and social inequality in the municipality of Afrânio-PE, inviting the reader to also reflect on what interferes in educational policies to strengthen Early Childhood Education, Proinfância program, pointing out proposals to remedy the lack of day-care centers, the increase of care of children in this modality of education. In this perspective, it is also imperative to admit that the persistent existence of the poor in schools brings fundamental analyzes to educational practices, with poor individuals being noticed by a large part of society, linked to violence and crimes, and who are not endowed with values, a teaching that fights the pejorative image of the poor, breaking with a moralistic curriculum, strengthening values of justice and citizenship, guaranteeing an inclusive education.
\end{abstract}

Keywords: Child education. Poverty. Social inequality.

\footnotetext{
${ }^{1}$ Professor de História. Especialista em Educação Pobreza e Desigualdade Social ( UFPE), Especialista em História do Brasil pela UCAMPROMINAS. Contato: ricardo-roddrigues@ hotmail.com

${ }_{2}^{2}$ Especialista em Ensino Superior, Contemporaneidade e Novas Tecnologias - UNIVASF; Mestranda em Extensão Rural UNIVASF. Contato: aitla.lidiane@univasf.edu.br
} 


\title{
Introdução
}

Em consonância com a Lei no 9.394/96, em seu Artigo 29, é preciso, incialmente frisar que a Educação Infantil é a primeira etapa da Educação Básica e tem como finalidade o desenvolvimento integral da criança de zero a cinco anos de idade em seus aspectos físico, afetivo, intelectual, linguístico e social, complementando a ação da família e da comunidade. O município de Afrânio-PE foi escolhido para a pesquisa, tendo em vista o que interfere nas políticas educacionais da educação infantil, pobreza e desigualdade social, no intuito de esclarecer ao leitor, através da observação e analise dos supracitados planos e sistemas, apontando possíveis gerenciamentos para a resolução dessa problemática, visando uma educação de qualidade.

Neste sentindo é pertinente registrar o que afirma a Resolução CNE/CEB nº 5/2009:

\begin{abstract}
$\mathrm{O}$ atendimento em creches e pré-escolas como um direito social das crianças se concretiza na Constituição de 1988, com o reconhecimento da Educação Infantil como dever do Estado com a Educação, processo que teve ampla participação dos movimentos comunitários, dos movimentos de mulheres, dos movimentos de redemocratização do país, além, evidentemente, das lutas dos próprios profissionais da educação. A partir desse novo ordenamento legal, creches e pré-escolas passaram a construir nova identidade na busca de superação de posições antagônicas e fragmentadas, sejam elas assistencialistas ou pautadas em uma perspectiva preparatória a etapas posteriores de escolarização.
\end{abstract}

Silva, Pasuch e Silva (2012) consideram que a Educação Infantil do campo tem princípios que devem ser considerados quando se pensa na relação entre a escola, a família e a comunidade às quais a criança pertence. Dentre eles, pode-se ressaltar:

\footnotetext{
- o acesso aos recursos da comunidade, da sociedade e de seu grupo cultural;

- o desenvolvimento de uma identidade da criança com seu grupo e consigo mesma, não sofrendo processos de discriminação de qualquer ordem;

- as possibilidades de interações significativas com o conhecimento cotidiano, científico, tecnológico, artístico da sociedade e de seu grupo cultural. (SILVA, PASUCH E SILVA, p. 153, 2012)
}

De acordo com os dados descritos, ao longo desse estudo apresentaremos um panorama sobre a Educação Infantil, dados socioeconômicos e o processo de implantação e implementação do Programa Nacional de Reestruturação e Aquisição de Equipamentos para a Rede Escolar Pública de Educação Infantil - Proinfância. 
O Programa Proinfância foi instituído pela Resolução $n^{\circ}$ 6, de 24 de abril de 2007, e é parte das ações do Plano de Desenvolvimento da Educação - PDE do Ministério da Educação, visando a construção de creches e a aquisição de equipamentos fundamentais à melhoria do ensino aprendizagem, através de assistência financeira.

O trabalho consiste num estudo de caso, realizado através de uma pesquisa qualitativa e análise de documentos, tendo como campos de pesquisas a Secretaria de Educação do Ensino Básico-SEEB, Conselho Municipal de Educação de Afrânio-CMEA, Escola Municipal Aureliano Francisco Neto e a Creche Tipo C - Padrão FNDE, ambas localizadas no Distrito de Extrema- Afrânio-PE.

Vale ressaltar que percorremos pelas teorias fundamentadas nas concepções de autores como: Arroyo (2012) que destaca um novo olhar sobre a gestão educacional e o enfrentamento as desigualdades: Sobre Educação e Sociedade, percorremos às teorias de Dayrell (2003) descreve: O jovem como sujeito social, Ferreiro (2002) atribui a escola como responsável pela homogeneização, não sabendo conviver as diferentes culturas. outro autor de destaque nesse estudo é Quijano (2005), o qual enfatiza a construção da pobreza integrada aos processos sociais e a condição de inferioridade e Silva, A. P. S.; Pasuch, J.; Silva (2012) que relatam a educação infantil no campo.

O estudo visa avaliar o Plano Municipal de Educação - PME 2015-2025, Plano de Ações Articuladas - PAR 2011-2014, dados dos Censos Demográficos de 2000 e 2010/ IBGE e do Sistema Integrado de Monitoramento Execução e Controle - SIMEC; Além de descrever as dificuldades que impedem o pleno funcionamento da Educação Infantil no município de Afrânio- PE.

O município de Afrânio-PE foi escolhido para a pesquisa, tendo em vista o que interfere nas políticas educacionais da Educação Infantil e enfrentamento da pobreza e desigualdade social, objetivando informar os diversos segmentos sociais, através da observação e analise dos supracitados planos e sistemas.

Diante do exposto, podemos refletir sobre o que impede o pleno funcionamento da Educação Infantil no município de Afrânio- PE e as possíveis ações do município para a resolução desse problema visando uma educação de qualidade. 


\section{Pobreza e Desigualdade Social no Contexto Educacional}

É evidente que a Constituição Federal de 1988 (BRASIL, 1988) tornou-se uma referência de extrema importância na execução de políticas educacionais para as crianças de 0 a 6 anos, a partir de uma propagação de princípios que garantem os seus direitos, inclusive o direito à Educação, sendo que capítulo dedicado aos Direitos Sociais, o Art. $7^{\circ}$, estabelece que são direitos dos trabalhadores urbanos e rurais, além de outros que visem à melhoria de sua condição social, a assistência gratuita aos filhos e dependentes desde o nascimento até aos seis anos de idade em creches e pré-escolas. (BRASIL, 1988).

Diante de uma situação de extrema pobreza, não é alarmante apenas a injustiça social, nota-se por outro lado também as causas que essas desigualdades trarão as crianças oriundas do círculo de pobreza tendo mais probabilidade de serem futuros cidadão pobres, dificultando a frequência assídua na escola, tendo que ocupar-se em atividades trabalhistas. Segundo Arroyo (2012), quando se imputa aos(às) pobres a sua condição de pobreza e considera-se que são carentes de valores, passa-se a entrever apenas uma solução: educá-los(as) nos valores do trabalho, da dedicação e da perseverança, desde a infância. Nesse sentido, a tarefa da escola diante de milhões de crianças e adolescentes na extrema pobreza seria de moralizá-los(as) nesses valores, que eles(as) supostamente não recebem das famílias e dos coletivos empobrecidos.

No entanto, observamos que os indivíduos pobres são vistos por grande parte da sociedade, ligados à violência e a crimes e que não são dotados de valores. Nota-se também que políticas públicas e os programas socioeducativos podem ser carregados de moralismos, sendo que essas representatividades é uma maneira errônea de atribuir para as instituições de ensino e aos seus professores a saída de uma problemática construída nos âmbitos socioeconômicos e políticos. Nesta direção, é importante salientar que, a produção dos (as) pobres é articulada e reforçada com os processos sociais que conferem assimetria à diversidade, reduzindo o diferente à condição de inferioridade. No contexto social e político, isso se deu pela expropriação violenta de suas terras, seus territórios, suas culturas, suas memórias, suas histórias, suas identidades, suas línguas, sua visão de mundo e de si mesmos(as). Esses coletivos foram decretados inferiores e mantidos à margem da produção intelectual, cultural e ética da humanidade (QUIJANO, 2005). 
É mister aceitar que os educandos possuem experiências diversificadas e que produzem suas ideias a partir delas, estimulando os professores a aprofundarem as práticas socioculturais de seus alunos-a realidade, os territórios, as formas de entender o mundo, integrando e relações entre o objeto de aprendizado e essas experiências, neste caso o professor não é um mero transmissor de conteúdos, mas aquele que valoriza a historicidade e a aprendizagem do estudante.

Nesta conjuntura, é preciso frisar o que nos aborda Ferreiro (2002), a escola, historicamente encarregada de homogeneizar, de igualar, nunca soube lidar com a diversidade. O resultado dessa falta de reconhecimento foi o surgimento do fracasso escolar, tão conhecido de crianças, jovens e adolescentes das camadas populares. Historicamente, as escolas e os(as) professores(as) sempre tiveram muita dificuldade para trabalhar com a diversidade: de cultura, etnia, gênero, vivência social e ritmos de aprendizagem.

É necessário, admitir que a existência persistente dos pobres nas escolas traz análises fundamentais para as práticas educacionais, sendo que os indivíduos pobres são notados por grande parte da sociedade, ligados à violência e a crimes e que não são dotados de valores, cabendo, um ensino que combate a imagem pejorativa do pobre, rompendo com um currículo moralista.

Levando em consideração a afirmação de Santo Mé (1995), “estudos têm mostrado práticas em sala de aula que transmitem sentimentos de inferioridade e discriminação a minorias étnicas, membros de diferentes religiões, estudantes oriundos de diferentes culturas", questiona se as propostas pedagógicas implementadas no espaço escolar, incentivam os professores a romperem com a visão moralista em relação à pobreza e desigualdade social.

Quando se trata da questão da vivência das propostas pedagógicas por parte dos professores, é bem verdade que as mesmas precisam ser repensadas e reestruturadas de forma a atender de maneira digna, justa e não discriminatória a pessoa que vive na pobreza, tendo em vista que não só as propostas estão carregadas dessa visão moralista, mas o próprio ambiente escolar, a sociedade e o seu entorno. 


\section{Metodologia}

O presente trabalho consiste num estudo de caso, realizado através de uma pesquisa qualitativa e análise de documentos, tendo como campos de pesquisas a Secretaria de Educação do Ensino Básico-SEEB, Conselho Municipal de Educação de Afrânio-CMEA, Escola Municipal Aureliano Francisco Neto e a Creche Tipo C - Padrão FNDE, ambas localizadas no Distrito de Extrema- Afrânio-PE.

É importante frisar que a Secretaria de Educação do Ensino Básico-SEEB é o órgão responsável pela Educação Básica (Educação Infantil, Ensino Fundamental, Educação Especial e Educação de Jovens e Adultos) no município de Afrânio-PE. Além desse Órgão, o município conta com o Conselho Municipal de Educação de Afrânio-CMEA, o qual foi criado pela Lei Municipal $n^{\circ}$ 282/2006 e alterado pela Lei Municipal $n^{\circ}$ 013/2011. Órgão consultivo e deliberativo do Poder Executivo à Política Municipal de Ensino.

Os sujeitos da pesquisa são os membros do CMEA, Coordenadores e Técnicos da SEEB e a comunidade escolar do Distrito de Extrema. Foram utilizados para análise da temática em estudo, a Constituição Federal- CF88, o Plano Municipal de Educação - PME 2015-2025, dados do Sistema Integrado de Monitoramento Execução e Controle/ Plano de Ações Articuladas SIMEC- PAR Instituto Brasileiro de Geografia e Estatística- IBGE, sendo exploradas também, as teorias fundamentadas nas concepções de autores como: Arroyo (2012), Dayrell (2003), Ferreiro (2002), Quijano (2005), Silva, A. P. S.; Pasuch, J.; Silva (2012).

\section{Resultados e Discussão}

\section{Proinfância no Município de Afrânio}

Através dos dados coletados, foi possível notar a necessidade de implantação e implementação do Proinfância no Município de Afrânio e considerando a demanda, conforme observada através do Censo do IBGE/2010, o qual demonstra que o município possui 1.166 crianças de 0 a 6 anos e 716 de 4 a 5 anos. 
De acordo com a Equipe Local do PAR (2016) é importante frisar que, o Município de Afrânio-PE no de 2011 apresentou 05 (Cinco) projetos junto ao Proinfância, visando adquirir equipamentos que viabilizem os padrões mínimos de qualidade do ensino, assim como à cobertura de despesa de investimentos na construção de creche, fomentando a disponibilidade dos pais trabalharem, diminuindo o elevado índice de distorção idade/séries na SEDE e Zona Rural nos Distritos de Cachoeira do Roberto, Poção e Arizona e Extrema.

Considerando que as quotas de creches arquivadas não foram reabertas para o município na seleção 2013/2014. Neste sentido deve-se aguardar a disponibilidade no SIMEC/PAR para inserir novas propostas de construção que posteriormente serão analisadas pelo Fundo Nacional de Desenvolvimento da Educação - FNDE, Diretoria de Gestão, Articulação e Projetos Educacionais - DIGAP e a Coordenação Geral de Implementação e Monitoramento de Projetos Educacionais - CGIMP.

O município já teve como problemática a paralisação da Creche tipo C /padrão FNDE na Zona Rural- Distrito de Extrema, sendo que esta obra, garantida através do Termo de Compromisso 1619/2011, de Afrânio/PE, foi paralisada por questões políticas.

Entretanto, como a paralisação da Creche do Distrito Extrema impedia a realização de novos atendimentos ao município, a Gestão Administrativa-2013-2016 abriu novo processo licitatório dando continuidade a implementação da obra, uma vez que a empresa contratada anteriormente, não tinha interesse na obra, reafirmando o compromisso e responsabilidade de concluí-la.

Conforme relatos do Comitê Gestor do Plano de Metas Compromisso todos pela Educação sob a portaria de n 109/2013 responsável pelo monitoramento do SIMEC/PAR 20132016 e a Coordenação Geral de Infraestrutura Educacional do FNDE: A prefeitura de Afrânio não estaria apta a solicitar recursos para construção de creches, em função dos critérios estabelecidos pelo Comitê gestor do Plano de Crescimento e Aceleramento - PAC II.

Vale enfatizar também que as paralisações em vistas ao Termo de Convênio n ${ }^{\circ}$ 70339/2010 que tem por objeto a construção de 03 (três) unidades escolares padrão FNDE no município, sendo elas as seguintes: Espaço educacional rural Recanto da Taboca; Construção de escola 02 (duas) salas padrão FNDE; Espaço educacional rural Poço do Angico; Construção de escola 02 (duas) salas padrão FNDE; Espaço educacional rural Araçá; Construção de escola 06 (seis) salas padrão FNDE; impossibilitam a administração firmar novos acordos em parceria com FNDE. 
No âmbito educacional do município de Afrânio, cabe salientar que a Escola Municipal Aureliano Francisco Neto, situada no Distrito de Extrema - Zona Rural a $22 \mathrm{~km}$ da sede do município, sob a jurisdição da Gerencia Regional de Educação do Sertão do Médio São Francisco- GRE, Petrolina - PE atende atualmente na Educação Infantil, 66 alunos (as), no Ensino Fundamental - Anos Iniciais 180 alunos (as) e no Ensino Fundamental - Anos Finais 153 alunos (as), totalizando 399 alunos. No respectivo distrito foi construída a primeira Creche padrão/ Fundo Nacional de Desenvolvimento da Educação- FNDE do município sendo um marco na educação de Afrânio.

\section{A Meta 1 do Plano Municipal de Educação-PME}

A Meta 1 do Plano Municipal de Educação-PME trata da universalização da Educação Infantil, na pré-escola para as crianças de 04 (quatro) a 05 (cinco) anos de idade e ampliar a oferta de Educação Infantil em creches, de forma a atender no mínimo 50\% (cinquenta por cento) das crianças de até 03 (três) anos, até o final da vigência do PME-2015-2025. No entanto, não se trata somente de garantir o acesso, mas de criar uma série de estratégias que contribuam para o desenvolvimento físico, psicológico, intelectual e social das crianças, tratando-as como sujeitos de direito e estimulando sua permanência.

\section{Percentual de crianças na escola}

Em consonância com a Meta 1 do Plano Municipal de Educação-PME citado anteriormente, segue demonstrativo do percentual de crianças de 4 e 5 anos e 0 a 3 anos na escola conforme Tabelas 1 e 2 .

Tabela 1 - Percentual de crianças de 4 e 5 anos na escola - Meta Brasil: 100\%

\begin{tabular}{c|c|c|c|c|c}
\hline Situação & Brasil & Nordeste & Pernambuco & $\begin{array}{c}\text { Sertão de } \\
\text { Pernambuco }\end{array}$ & $\begin{array}{c}\text { Município de } \\
\text { Afrânio }\end{array}$ \\
\hline$\%$ & 81,4 & 87,0 & 82,1 & 77,7 & 80,7 \\
\hline
\end{tabular}

${ }^{1}$ Fonte: IBGE (2010 / 2013)

${ }^{1}$ Fonte: Estado, Região e Brasil - IBGE/Pesquisa Nacional por Amostra de Domicílios (PNAD) - 2013 Município e Mesorregião - IBGE/Censo Populacional - 2010 
Vale salientar que o percentual de crianças de 5 e 4 anos que frequenta a escola são 80,7\%. Contudo, é notório que faz-se necessário a implantação e execução de politicas educacionais, no que tange, a construção de novos espaços educativos.

Tabela 2 - Percentual da população de 0 e 3 anos que frequenta a escola - Meta Brasil: 50\%

\begin{tabular}{c|c|c|c|c|c}
\hline Situação & Brasil & Nordeste & Pernambuco & $\begin{array}{c}\text { Sertão de } \\
\text { Pernambuco }\end{array}$ & $\begin{array}{c}\text { Município de } \\
\text { Afrânio }\end{array}$ \\
\hline$\%$ & 23,2 & 19,2 & 20,7 & 14,3 & 6,2 \\
\hline
\end{tabular}

${ }^{2}$ Fonte: IBGE (2010 / 2013)

É notório que no município de Afrânio, o atendimento às crianças de 0 a 3 anos ainda é incipiente, por isso é imprescindível que o município atue em regime de colaboração com os outros entes para buscar os meios de se garantir essa oferta.

Observa-se que o município não cumpriu com as diligências técnicas solicitadas pela equipe de Engenharia do Fundo Nacional de Desenvolvimento da Educação - FNDE sendo arquivados 4 (quatro) projetos de creches em 2011, de acordo com os respectivos pareceres do FNDE fundamentados em dados do SIMEC/PAR como podemos notar nas imagens a seguir:

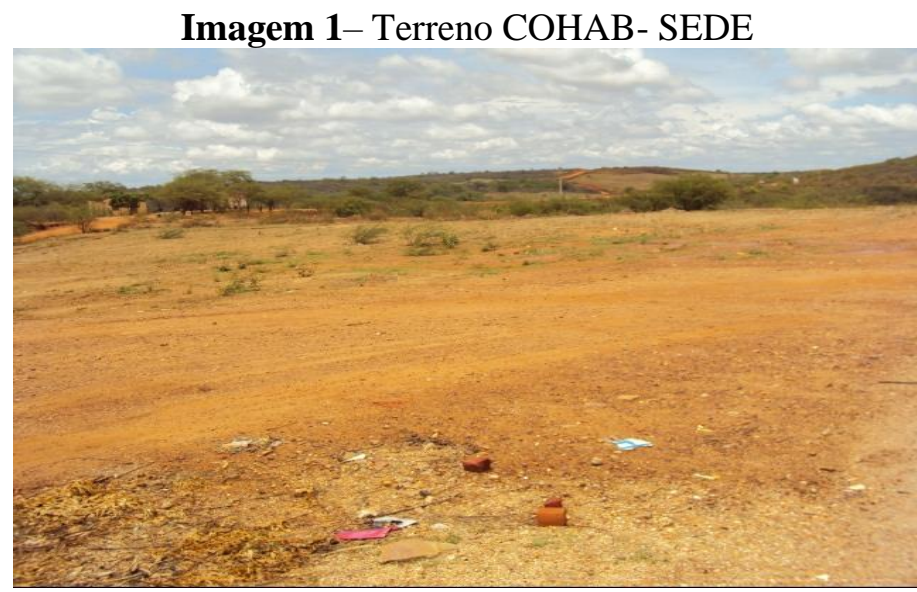

${ }^{3}$ Fonte: SIMEC/PAR ( 2010)

\footnotetext{
${ }^{2}$ Estado, Região e Brasil - IBGE/Pesquisa Nacional por Amostra de Domicílios (PNAD) - 2013 Município e Mesorregião - IBGE/Censo Populacional - 2010

${ }^{3} \mathrm{http}: / /$ simec.mec.gov.br/slideshow/slideshow/index.php?pagina $=\&$ _sisarquivo=obras \&arqid $=581918$ 
Em relação às informações sobre o terreno não foi possível identificar a sua localização dentro da malha urbana do município. Para aprovação da obra pelo FNDE, segundo o SIMECPAR deverá ser enviado Planta de Localização que possibilite a identificação do terreno inserido na malha urbana do município.

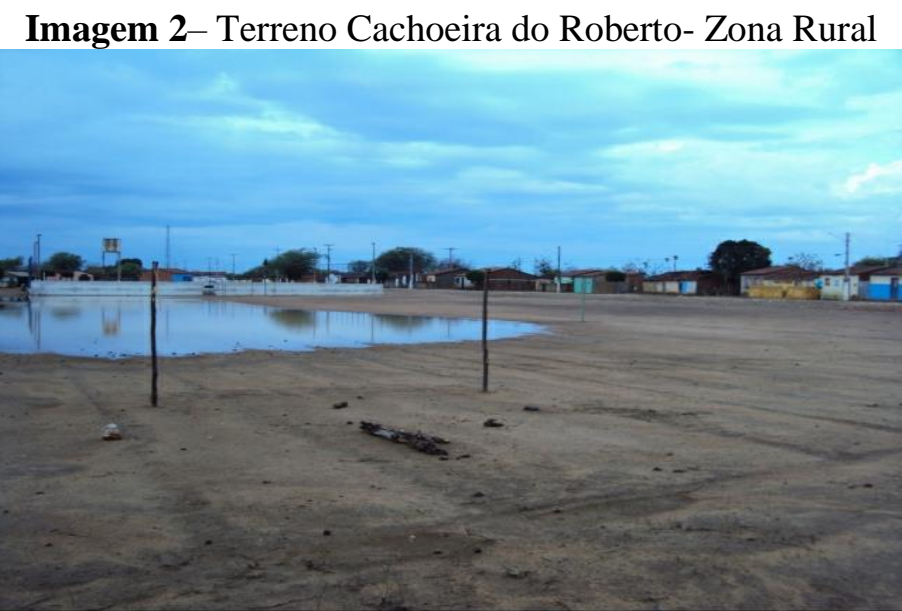

${ }^{4}$ Fonte: SIMEC/PAR ( 2010)

Vale ressaltar que mesmo não encontrando pendências em relação ao cadastro de dados no SIMEC- PAR o projeto para construção de espaço de educação Infantil no Distrito de Cahoeira do Roberto- Zona Rural do Município, também foi arquivado de acordo com FNDE por não cumprir diligências técnicas.

Imagem 3- Terreno Arizona - Zona Rural

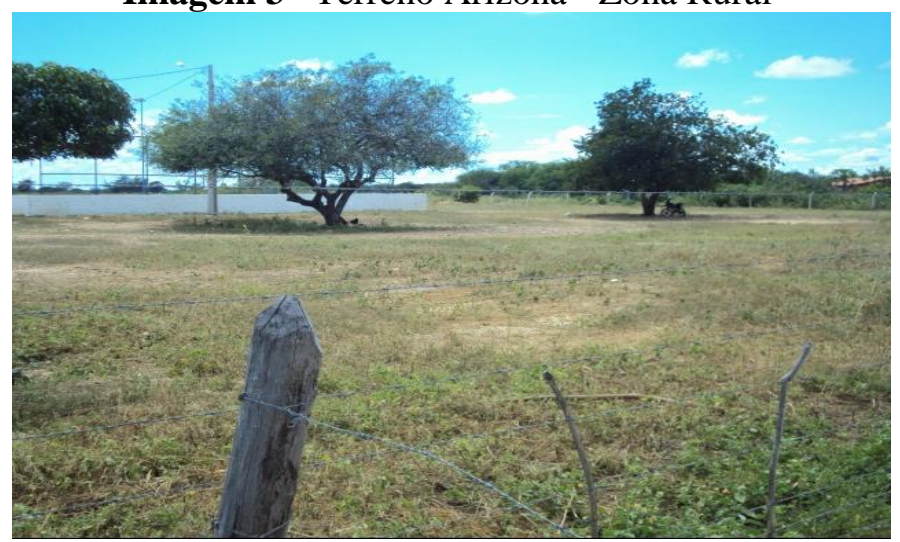

${ }^{5}$ Fonte: SIMEC/PAR ( 2011)

\footnotetext{
${ }^{4}$ http://simec.mec.gov.br/slideshow/slideshow/index.php?pagina=\&_sisarquivo=obras\&arqid=557451

5 http://simec.mec.gov.br/slideshow/slideshow/index.php?pagina=\&_sisarquivo=obras\&arqid=945471 
Sobre o arquivamento do Projeto para construção de Escola Infantil no Distrito de Arizona, pode-se afirma em consonância com o FNDE que para ser implantada uma creche, os usuários deverão percorrer uma distância de aproximadamente 500 metros da residência até a Creche. No entanto, a localidade de Arizona não apresentou demanda consolidada nas proximidades do terreno disponibilizado. É preciso destacar também que o relatório fotográfico enviado não foi suficiente para comprovar que na comunidade indicada existe uma demanda concreta.

Imagem 4- Terreno Poção - Zona Rural

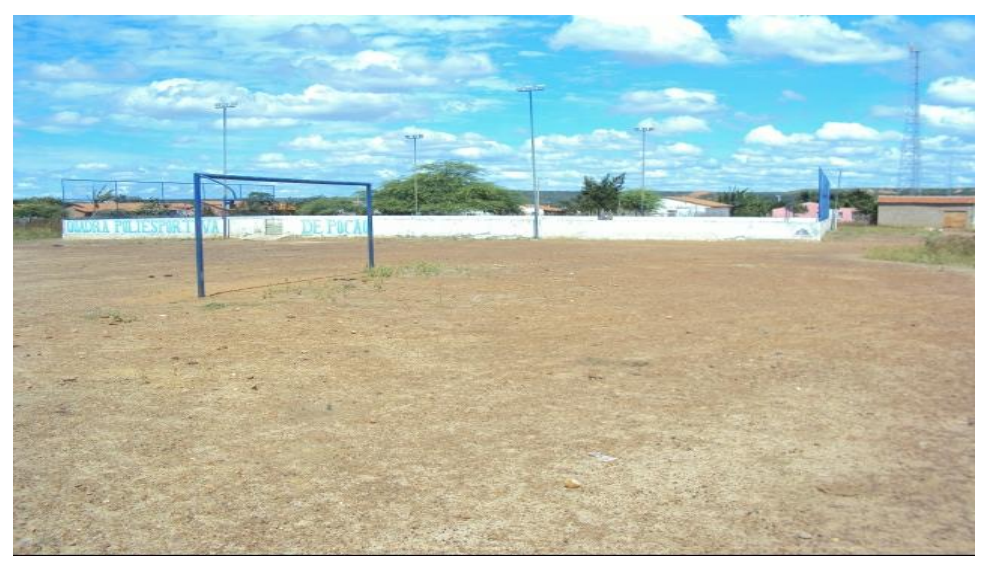

${ }^{6}$ Fonte: SIMEC/PAR (2011)

No Projeto citado anteriormente, o FNDE recomendou também que para implantação de uma creche, o usuário deveria percorrer uma distância de 500 metros aproximadamente entre a residência e a escola. As fotos não foram suficientes para comprovar demanda consolidada nas proximidades. Neste sentido o Distrito de Poção também não apresentou demanda nas proximidades do terreno escolhido.

Portanto mesmo com a paralisação do projeto das creches, a primeira creche do município foi concluída em 2016 como pode ser visto na Imagem 5. No ano de 2017 atendeu 66 crianças na modalidade de Educação Infantil pertencentes à Escola Municipal Aureliano Francisco Neto que utiliza o espaço educativo como extensão. Porém, não está em pleno funcionamento como exigido pelo Proinfância, inclusive a creche não foi mobiliada, de acordo com o termo de compromisso firmado.

\footnotetext{
${ }^{6}$ http://simec.mec.gov.br/slideshow/slideshow/index.php?pagina=\&_sisarquivo=obras\&arqid=945437 
Imagem 5- Creche Padrão FNDE- Tipo C

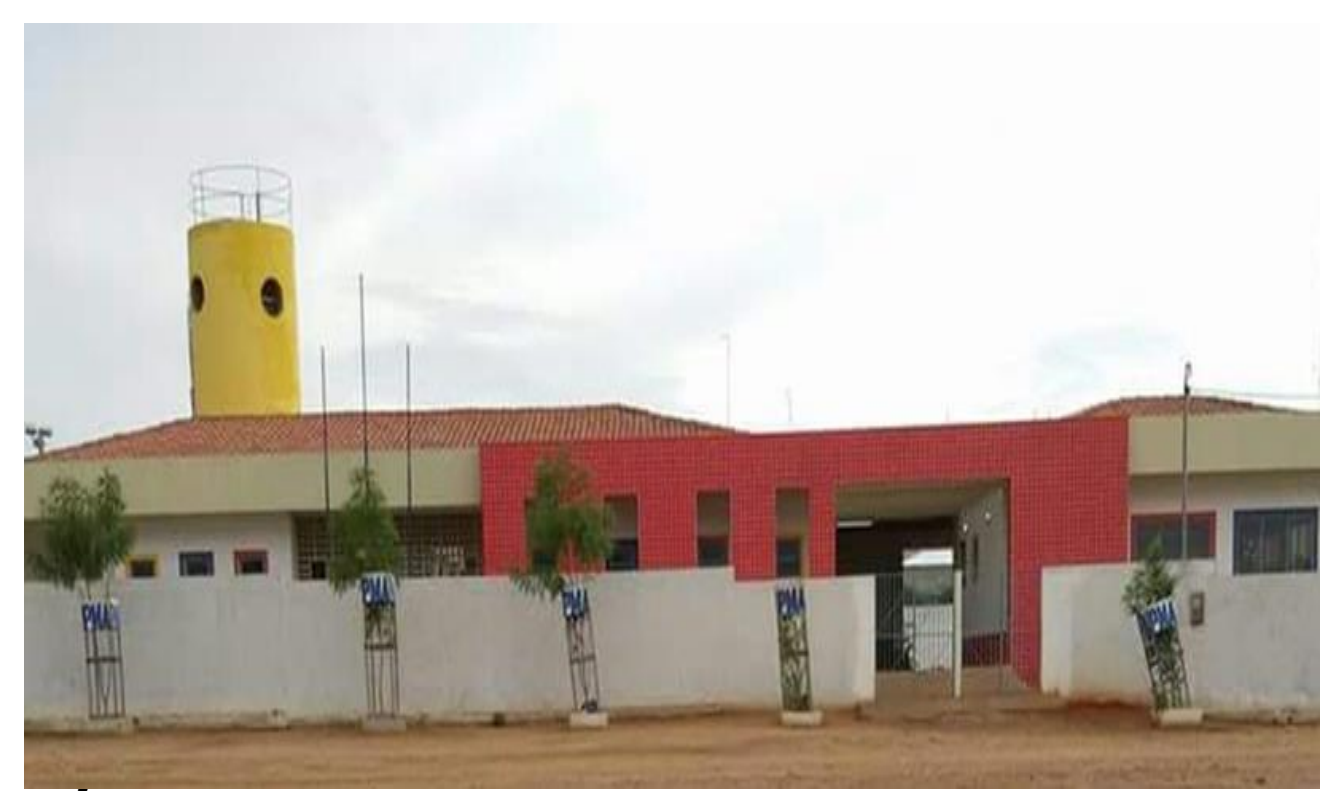

${ }^{7}$ Fonte: Foto retirada da internet - Creche- Padrão FNDE- Distrito de Extrema- Afrânio- PE

Para aprofundar a reflexão sobre essas questões é salutar analisar dados sobre os aspectos sociodemográficos da população do município de Afrânio que ampliou, entre os Censos Demográficos de 2000 e 2010, à taxa de 1,60\% ao ano, passando de 15.007 para 17.586 habitantes.

Quanto aos níveis de pobreza em Afrânio, em termos proporcionais, 29,9\% da população está na extrema pobreza, com intensidade maior na área rural (37,1\% da população na extrema pobreza na área rural contra $15,4 \%$ na área urbana, conforme demonstra o Gráfico 1.

Gráfico 1 - Participação da população extremamente pobre no município e no estado por situação do domícilio em 2010

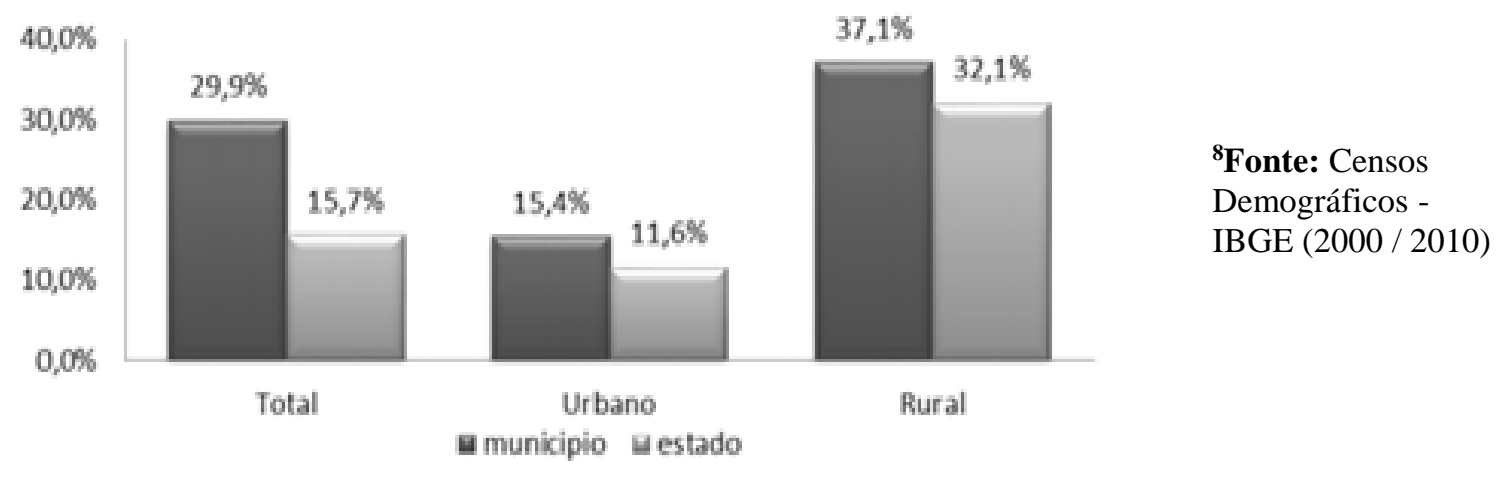

\footnotetext{
${ }^{7}$ https://www.facebook.com/extrema.afranio?ref=br_rs

${ }^{8}$ Censos Demográficos - IBGE (2000 / 2010) 
No que concerne também à caracterização demográfica da extrema pobreza conforme dados do Censo IBGE 2010, a população total do município de Afrânio-PE era de 17.586 residentes, dos quais 4.891 encontravam-se em situação de extrema pobreza, ou seja, com renda domiciliar per capita abaixo de $\mathrm{R} \$ 70,00$. Isto significa que $27,8 \%$ da população municipal vivia nesta situação.

De acordo com a Tabela 3, o Censo também revelou que no município havia 432 crianças na extrema pobreza na faixa de 0 a 3 anos e 266 na faixa entre 4 e 5 anos. $O$ grupo de 6 a 14 anos, por sua vez, totalizou 1.305 indivíduos na extrema pobreza, enquanto no grupo de 15 a 17 anos havia 318 jovens nessa situação. Foram registradas 51 pessoas com mais de 65 anos na extrema pobreza. $47,4 \%$ dos extremamente pobres do município têm de zero a 17 anos.

Tabela 3 - População em situação de extrema pobreza por faixa etária

\begin{tabular}{c|c}
\hline Idade & Quantidade \\
\hline 0 a 3 & 432 \\
\hline 4 a 5 & 266 \\
\hline 6 a 14 & 1305 \\
\hline 15 a 17 & 318 \\
\hline 18 a 39 & 1666 \\
\hline 40 a 59 & 853 \\
\hline 65 ou mais & 51 \\
\hline Total & 4891 \\
\hline
\end{tabular}

${ }^{9}$ Fonte: Instituto Brasileiro de Geografia e Estatística (2010).

O Censo de 2010 revelou que no município havia 400 crianças de 0 a 3 anos na extrema pobreza não frequentando creche, o que representa 92,6\% das crianças extremamente pobres nessa faixa etária. Entre aquelas de 4 a 5 anos, havia 65 crianças fora da escola $(24,3 \%$ das crianças extremamente pobres nessa faixa etária) e, no grupo de 6 a 14 anos, eram 27 (2,0\%).

\section{Considerações Finais}

Em suma, o presente estudo é relevante para que os cidadãos possam refletir sobre o panorama da Educação Infantil, pobreza e desigualdade social, e especificamente, a situação do

\footnotetext{
${ }^{9}$ Censo Demográfico - IBGE ( 2010)
} 
programa Proinfância no município de Afrânio-PE, informando os diversos segmentos sociais sobre o que interfere nas políticas educacionais de fortalecimento da Educação Infantil, apresentando propostas para sanar o problema.

Entretanto, a partir da análise dos dados obtidos no Plano Municipal de Educação - PME 2015-2025, Sistema Integrado de Monitoramento Execução e Controle/ Plano de Ações Articuladas - SIMEC- PAR é possível deduzir que o município já recebeu recursos para as obras supracitadas e as mesmas apresentam pendências em sua execução. Enquanto o problema não for sanado, o FNDE não procederá a análise de novas demandas de obras, tampouco efetuará novos Termos de Compromissos.

Segundo o Censo de 2010, o município obtinha 400 crianças de 0 a 3 anos na extrema pobreza não frequentando creche, o que representa 92,6\% das crianças extremamente pobres nessa faixa etária. Entre aquelas de 4 a 5 anos, havia 65 crianças fora da escola $(24,3 \%$ das crianças extremamente pobres nessa faixa etária) e, no grupo de 6 a 14 anos, eram 27 (2,0\%). Conforme a Meta 1 do Plano Municipal de Educação-PME-2015-2025, o percentual de crianças de 0 e 3 anos que frequenta a escola são 6,2\%, um resultado incipiente sendo fundamental para que o município atue em regime de colaboração com os outros entes para buscar os meios de se garantir essa oferta. Cabe frisar também que o percentual de crianças de 5 e 4 anos que frequenta a escola são $80,7 \%$.

Dessa forma, diante do que foi mostrado é preciso a implantação e execução de politicas educacionais, no que se refere, a construção de novos espaços educativos, mobiliados e adequados conforme faixa etárias; a regularização e pleno funcionamento da primeira creche do município que mesmo ofertando a Educação Infantil, o espaço funciona como extensão da Escola Municipal Aureliano Francisco Neto; e o aumento da oferta de crianças em extrema pobreza nas creches, com o intuito de promover o desenvolvimento integral, combatendo a imagem pejorativa dos pobres, pois são notados por grande parte da sociedade, ligados à violência e a crimes e que não são dotados de valores, rompendo com um currículo moralista, fortalecendo valores de justiça, cidadania e respeito.

\section{Referências}

AFRÂNIO. Lei n ${ }^{\circ}$ 479, de 23 de junho de 2015, Aprova o Plano Municipal de Educação. 
ARROYO, Miguel Gonzalez. Os coletivos empobrecidos repolitizam os currículos. In: SACRISTÁN, José Gimeno (Org.). Saberes e incertezas sobre o currículo. Porto Alegre: Penso, 2013.

Corpos precarizados que interrogam nossa ética profissional. In: ARROYO, Miguel G.; SILVA, Maurício R. da (Org.). Corpo-infância: exercícios tensos de ser criança; por outras pedagogias dos corpos. Petrópolis: Vozes, 2012. p. 23-54.

Outros sujeitos, outras pedagogias. Petrópolis: Vozes, 2012.

Políticas educacionais e desigualdades: à procura de novos significados. Educação e

Sociedade. Campinas, v.31, n. 113, out./dez. 2010. Disponível em: <http://www.scielo.br/pdf/es/v31n113/17>. Acesso em: 3 mai. 2018.

BRASIL. Constituição (1988). Constituição da República Federativa do Brasil. Brasília, DF: Senado, 1988.

BRASIL. IBGE. Cidades. Disponível em: http://www.cidades.ibge.gov.br/Acesso em 12 de Outubro de 2017.

BRASIL. Ministério da Educação. Diretrizes Curriculares Nacionais para a Educação Infantil. Resolução CNE/CEB nº 5/2009.

FERREIRO, Emília. Passado e presente dos verbos ler e escrever. São Paulo: Cortez, 2002.

IBGE. Censo Demográfico 2010, Instituto Brasileiro de Geografia e Estatística.

PROGRAMA NACIONAL DE REESTRUTURAÇÃO E AQUISIÇÃO DE EQUIPAMENTOS PARA A REDE ESCOLAR PÚBLICA DE EDUCAÇÃO INFANTIL PROINFÂNCIA - (Resolução no 6, de 24 de abril de 2007 e anexos I e II).

QUIJANO, Aníbal. Colonialidade do poder, eurocentrismo e América Latina. In: LANDER, Edgardo (Org.). A colonialidade do saber: eurocentrismo e ciências sociais. Buenos Aires: Clacso, 2005.

RESOLUÇÃO CNE/CEB no 5/2009, que define Diretrizes Curriculares Nacionais para a Educação Infantil, com fundamento no Parecer CNE/CEB nº 20/2009.

SANTOMÉ, J.T. As culturas negadas e silenciadas no currículo. In: SILVA, T.T. (Org.). Alienígenas em sala de aula: uma introdução aos estudos culturais em educação. Petrópolis: Vozes, 1995. 
SIMEC: obras do PAR. Disponível <http://simec.mec.gov.br/par/par.php?modulo=principal/listaObrasParUnidade\&acao=A> Acesso em: 19 mai. 2018.

SILVA, A. P. S.; PASUCH, J.; SILVA, J. B. Educação Infantil do campo. São Paulo: Cortez, 2012.

\section{Como citar este artigo (Formato ABNT):}

RODRIGUES, Ricardo de Araujo; JATOBÁ, Aítla Lidiane Hermógenes de Souza.Um Estudo de Caso sobre a Educação Infantil, Pobreza e Desigualdade Social no Município de Afrânio- PE. Id on Line Rev.Mult. Psic., 2018, vol.12, n.42, p. 279-294. ISSN: 1981-1179.

Recebido: 23/08/2018;

Aceito: 06/09/2018 